valves, which prevent the air passing inwards. There are always one or more sides on which the wind does not blow, allowing the foul air free egress from within out. Some of the school buildings where this system has been introduced are having as much air passed through them as will refill the rooms every Io or I 5 minutes.

This system, as explained, can be seen in operation at the chemical laboratory of the Dundee University College, the Harris Academy, Dundee, and at the Dundee High Schools, the directors of which are introducing the system into another large new school for girls, which is to be opened in a few months.

Dundee, January 12

\section{A Family of Rare Java Snakes}

AT the Zoological Gardens, on Saturday, the 9th inst., a rather rare "Green. Tree Snake" (Dryiophis prasina), from Java, produced eight snakelings under circumstances which tend to confirm recent observations regarding the uncertain period of gestation in snakes, otherwise the voluntary retention or deposition of their eggs or even their young. The mother was brought to the Reptilum five months ago (August 15 ), and allowing two months for her transportation from Java, it must be at least seven months since she was captured and separated from her mate. The normal period of gestation in a snake of this size may be about three months, but incubation, which begins at once, would in all snakes seem to depend a good deal on temperature and on other propitious circumstances; nor can it be positively asserted that such or such a species is invariably oviparous or viviparous, as in several instances the same snake has been known to be both-i.e. under certain conditions an oviparous snake has become viviparous. In sunny weather a high temperature is obtained in the cages where this snake is; and it is probable that the late cold season may have materially affected this Dryiophis. It is probable that, lacking the dense foliage of her native forests, together with these adverse conditions of her small glass dwelling, she retained her progeny until the latest moment.

The snakelings average 20 inches in length. The mother is over 5 feet, and like all the family of whip-snakes is exceedingly slender, with the long tail tapering to a cord-like fineness. She is of a bright emerald green, while the little ones are of a dull ashy hue, with tongues of the same colour ; the mother's tongue is pinkish. The parent has fed well on small lizards during her captivity, but it is to be feared that the little family will fare badly, as at the present time suitable food is difficult to procure. They were at once removed into another cage, or their mother might have reduced their numbers at dinner-time. They soon found their way to the water-pan and drank freely, and began to cast their skins at an early day.

I5, Queen's Crescent, Haverstock Hill, N.W.

\section{Catherine C. Hopley}

\section{Vibration of Telegraph-Wires}

I NOTICED to-day a curious vibration of telegraph-wires near here, and perhaps some reader of NATURE may be able to explain it. Each wire was vibrating rapidly, but iustead of the nodes being only at each post, there were several in each span (of about 88 yards). The number of nodes varied in each span; I counted seven in one, nor did the wires vibrate together as a rule. In some spans four out of five wires were vibrating, and in others only one. The total amplitude of vibration did got exceed $I_{\frac{1}{2}}$ inches, $I$ should think. I noticed this peculiar action in some five or six contiguous spans only. There was a very hard frost at the time, and the wires were coated with snow which had fallen some thirty-six hours previously. There was no wind, and the sun was just breaking through a fog. The wire was galvanised iron, No. 8 B.W.G.

Howden, East Yorkshire, January I9

E. DE M. MALAN

\section{HEREDITARY STATURE 1}

I T will perhaps be recollected that, at the meeting last autumn of the British Association in Aberdeen, I chose for my Presidential Address to the Anthropological

${ }^{2}$ Extracts from Mr. F. Galton's Presidential Address to the Anthropological Institute, January 26 .
Section a portion of the wide subject of "Hereditary Stature." My inquiries were at that time advanced only to a certain stage, but they have since been completed up to a well-defined resting-place, and it is to their principal net results that I shall ask your attention to-night.

I am, happily, released from any necessity of fatiguing you with details, or of imposing on myself the almost impossible task of explaining a great deal of technical work in popular language, because all these details have just been laid before the Royal Society, and will in due course appear in their Proceedings. They deal with ideas that are perfectly simple in themselves, but many of which are new and most are unfamiliar, and therefore difficult to apprehend at once. My work also required to be tested and cross-tested by mathematical processes of a very technical kind, dependent in part on new problems, for the solution of which I have been greatly indebted to the friendly aid of Mr. J. D. Hamilton Dickson, Fellow and Tutor of St. Feter's College, Cambridge. I shall therefore quite disembarrass myself on the present occasion from the sense of any necessity of going far into explanations, referring those who wish thoroughly to understand the grounds upon which my results are based, to the forthcoming memoir in the Proceedings of the Royal Society, and to that amplified and illustrated extract from my Address at Aberdeen, accompanied by tabular data, which appeared among the "Miscellanea " of the Fournal of this Institute last November.

The main problem I had in view was to solve the following question. Given a group of men, all of the same stature, whatever that stature may be,-it is required to be able to predict two facts regarding their brothers, their sons, their nephews, and their grandchildren, respectively, namely, first, what will be their average height; secondly, what will be the percentage of those kinsmen whose statures will range between any two heights we may please to specify;-as between 6 feet and 6 feet I inch, 6 feet 1 inch and 6 feet 2 inches, \&c. ?

The same problem admits of another rendering, because whatever is statistically certuin in a large number is the most probable occurrence in a small one, so we may phrase it thus: Given a man of known stature, and ignoring every other fact, what will be the most probable average height of his brothers, sons, neplews, grandchildren, \&c., respectively, and what proportion of them will most probably range between any two heights we may please to specify?

I have solved this problem with completeness in a practical sense. No doubt my formula admit of extension to include influences of a minor kind, which I am content to disregard, and that more exact and copious observations may slightly correct the values of the constants I use; but I believe that for the general purposes of understanding the nearness of kinship in stature that subsists between relations in different degrees, the problem is solved.

It is needless to say that I look upon this inquiry into stature as a representative one. The peculiarities of stature are that the paternal and maternal contributions blend freely, and that selection, whether under the aspect of marriage selection or of the survival of the fittest, takes little account of it. My results are presumably true, with a few further reservations, of all qualities or faculties that possess these characteristics.

Average Statures. - The solution of the problem as regards the average height of the kinsmen proves to be almost absurdly simple, and not only so, but it is explained most easily by a working model that altogether supersedes the trouble of calculation. I exhibit one of these : it is a large card ruled with horizontal lines I inch apart, and numbered consecutively in feet and inches, the value of 5 feet 8 inches lying about half way up. A pin-hole is bored near the left-hand margin at a height corresponding to 5 feet $8 \frac{1}{4}$ inches. A thread secured at. 